\title{
IOT-BASED HOME APPLIANCE SYSTEM (SMART FAN)
}

\author{
${ }^{1}$ Mehran Ektesabi, Saman A. Gorji, Amir Moradi, \\ ${ }^{2}$ Suchart Yammen, V. Mahesh K. Reddy, \\ ${ }^{3}$ Sureerat Tang \\ ${ }^{1}$ Swinburne University of Technology, Victoria, Australia \\ ${ }^{2}$ Naresuan University, Thailand \\ ${ }^{3}$ TJ Supply Limited Partnership, Thailand
}

\begin{abstract}
Smart home appliances such as smart fridge, smart lighting, and smart air conditioner are getting popular for home end users. Smart fans as one of those smart devices are a part of a smart home that can be assumed as a factor of comfort, which may also reduce the electricity cost due to its high efficiency.

Hence, this project aims to develop an alternative smart fan tackled from a comfort and cost perspectives. This project is done using as minimum budget as possible by using a combination of the already-available parts of the market.

It is expected to develop a prototype of a cheap smart fan, which in turn becomes the starting point to allow further development of other smart home appliances
\end{abstract}

\section{KEYWORDS}

Internet of Things, Smart Fan, Motor Control, Cost Analysis, Cloud Infrastructure

\section{INTRODUCTION}

Automation has become one of the key interests in the modern-day technology. Everybody tends to use automated devices in his or her daily activities due to several reasons ranging from safety to ease of handling. Initially, the automation systems were limited to industries as it required significant investments, but with the development of the technology, automation has become available to everyone. Home automation systems are very popular in the world these days. Many types of research have been carried out into this area, and some commercial products are also available, but the room for development is still very high, and the technology advances daily. Unlike the normal system, the automated home will have additional benefits. As the electric system is automated, it will save electricity by switching off the appliances when they are not required. On the other hand, as the appliances can be remotely controlled, the user can decide what to do even he is not at home. The systems can be developed to a level where the security of the house can be improved. One of the famous home automation solutions is to use a dedicated system connected to an application installed on the user's smartphone. The combination of these two hardware and software allows greater control over home automation and put it all in the user's hand. 
Smart Technology has been chosen by many researchers and worked on different methodologies to achieve their objectives. As an instance a team worked on Smart fan robot which detects and tracks a person automatically using thermal camera and RGB-D camera [1].Another research study was done on human tracking system by using ultrasonic distance sensors to detect one person only up to 3 meters [2]. PWM technique is also used to control the fan speed by changing the duty cycle according to room temperature [3]. Also a group have developed a smart fan which operates according to the presence of human, ambient temperature and the position of humans [4]. Another project is done on controlling home appliances using smart phone with Wi-Fi as communication protocol and Raspberry Pi as a server system [5]. Another research team have conducted different tests and concluded that the fan speed can controlled by room temperature using PT-100 sensor [6]. Similar work was done on automatic fan speed control using PIC microcontroller. The authors used a special feature called Buzzer which generates alarm if the temperature becomes overheat [7]. Another group have designed a room temperature and humidity controller by using two fuzzy logic controllers. Their model is operated in between 8 and $44{ }^{\circ} \mathrm{C}$ rage of temperature and they proved that their model works properly between 18 and $26{ }^{0} \mathrm{C}$ temperature range in order to maintain the user comfort level [8]. The power electronics system can aid to implement more efficient systems [9]-[10]. In this area, a study has introduced a new method of speed control of induction motor by connecting power electronic circuit. This shows the increase in efficiency of the fan motor at low speeds and also starting torque is high at any speed value [11]. As an extension to these works done so far, in this project we interfaced Internet of Things (IoT) to the fan speed control by conducting the following techniques: IoT based motor control, Zero crossing Detection, Phase Angle Control (Triac Control) and Closed Loop Control to achieve the automatic speed control of the fan in an efficient way which becomes more user friendly to the human.

\section{SYSTEM REQUIREMENTS}

Automation has become one of the key areas which world focus at present. People tend to modify things which are often used so that they can be controlled by themselves or remotely by human intervention. With the invention of smartphones everything on earth has become possible with few clicks. In that type of an environment, it is important to have a user-friendly system where the devices in a house can be remotely controlled using a mobile phone. Through this project, we expect to make a smart fan which can be controlled via Bluetooth using an android application. Day to day normal room fans does not take the room temperature in to account we have to manually control the speed of the fan according to the temperature. We try to automate this system where the speed of the motor of the fan will change according to the temperature of the room. Table 1 shows the problem/need statement of this project.

Table 1. The project need statement

\begin{tabular}{l|l} 
Element & Description \\
\hline $\begin{array}{l}\text { The problem of } \\
\text { existing } \\
\text { conventional Fans }\end{array}$ & $\begin{array}{l}\text { In case of ceiling fan, table fans or pedal fans etc., the speed can be varied at step wise } \\
\text { only three steps. The user needs to control it manually which makes difficult in some } \\
\text { cases. When the user needs to increase or decrease the speed based on his comfort } \\
\text { level, he or she operates it manually every time. In addition, the power consumption is } \\
\text { high, and air flow is less in conventional fans. }\end{array}$ \\
\hline Affects & $\begin{array}{l}\text { Some users like aged persons, physically handicapped people mainly feel problematic } \\
\text { to control the fan every time manually when they need change in air flow. }\end{array}$ \\
\hline And results in & $\begin{array}{l}\text { User feels discomfort with this type of drawbacks; therefore, the manufacturing } \\
\text { company loses its stakeholders. }\end{array}$ \\
\hline $\begin{array}{l}\text { Benefits of a } \\
\text { solution }\end{array}$ & $\begin{array}{l}\text { The proposed control method solves these problems where user can control fan } \\
\text { remotely and also improves the customer comfort levels automatically. }\end{array}$
\end{tabular}




\section{ARCHITECTURE DESIGN}

For an IoT device to work, it required an architecture of hardware and software that supports the operation of IoT devices. This has been elaborated in the following subsections:

The supporting architecture could be categorised into many forms, depending on which part the focus lies. One of the categories is based on whether it is a hardware or software. Hardware architecture including but not limited to the gateway, cloud infrastructures, and even connectivity to the cloud interfaces. Software architecture including device management, the operating system of any hardware infrastructures, and also including communication protocol. Although there are many components which exists in the supporting architecture, we will focus more on the elements which are the core of IoT applications.



Figure 1. Generic Connection Architecture of an IoT Application

For small-scale IoT applications - such as temperature aware smart fan - does not need many supporting platforms. Some of the supporting platforms is not essential to the operation, and excluding those things could improve the development time of the system. Elements such as device management, provisioning, access controller, and resource allocation are useful, but its presence is not critical to a small-scale IoT application.

Small-scale IoT applications usually have a connection architecture as one placed in Figure 1. For this type of architecture, there are four essential elements: IoT Device, Gateway, Cloud Infrastructure, and Controller.

\section{IoT Device}

This device acts as the main element of the IoT applications. IoT device is a device which connects the whole IoT application to the physical world. Some examples of this connection are a temperature sensor, motor controller, building alarm, or even a webcam. 


\section{Gateway}

The gateway acts as a middle layer service between IoT devices, with the internet or another type of communication carrier to the cloud infrastructure. This device is usually also capable of communication processing, and also device management. Depending on the gateway design, this device could reach all layers in OSI model. So, the function of the gateway is various; it depends on the applications and the system's requirements.

\section{Cloud Infrastructure}

This element stores and process the data for/from the IoT devices. Depending on the application, this element could function as a database, or even as a smart decision server.

\section{Controller}

This element acts as the user interface for the system. Users could control and manage the behaviour of the applications.

\section{EXPERIMENTAL RESULTS}

\subsection{Motor Controller Results}

The motor was tested by TRIode for Alternating Current (TRIAC). Because Triac controller circuit runs on $240 \mathrm{~V}$, there are two steps for testing this Triac-based controller. The first one is by testing it on $20 \mathrm{Vpp}$, and the latter part is testing on $240 \mathrm{RMS}$ live voltage.

The first part used a signal generator as the voltage source, and an oscilloscope is used to read the voltage level at a different point in the circuit.

Next is to test the output of the triac. For this test, the firing is set to be constant at 90 degrees, and the voltage across triac terminal is observed on the oscilloscope. In Figure 2.a- Figure 2.b, there are three signals: blue for zero-crossing, purple for triac firing control, and green for the terminal-to-terminal voltage. As can be seen in the graph, when the purple signal is set to high, the terminal voltage (green) drops to a constant. This result concluded that the triac is working.

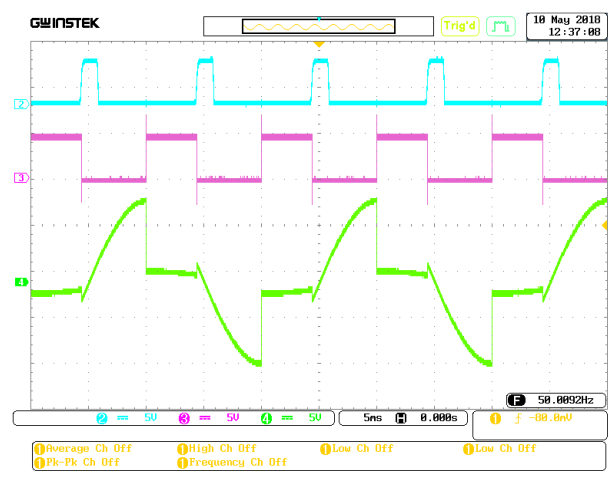

Figure 2.a Triac Functional Testing (90 degrees)

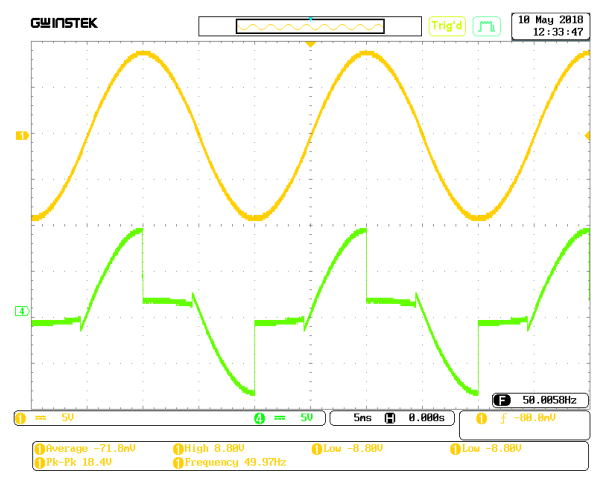

Figure 2.b Triac Terminal vs Source Voltage 


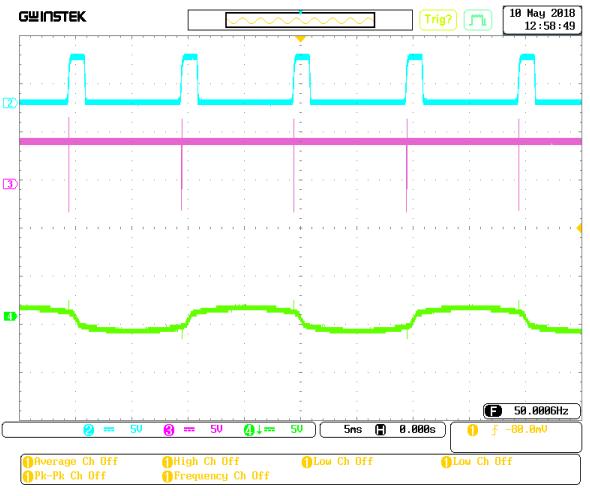

Figure 2.c Test with Firing Angle at 0 degree

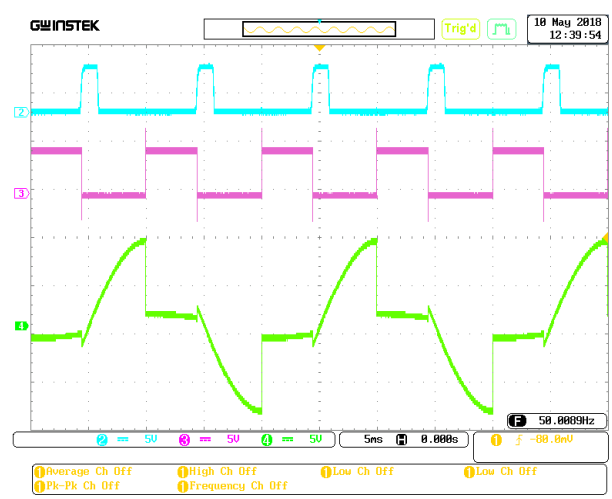

Figure 2.e Test with Firing Angle at 135 degrees



Figure 2.d Test with Firing Angle at 45 degrees

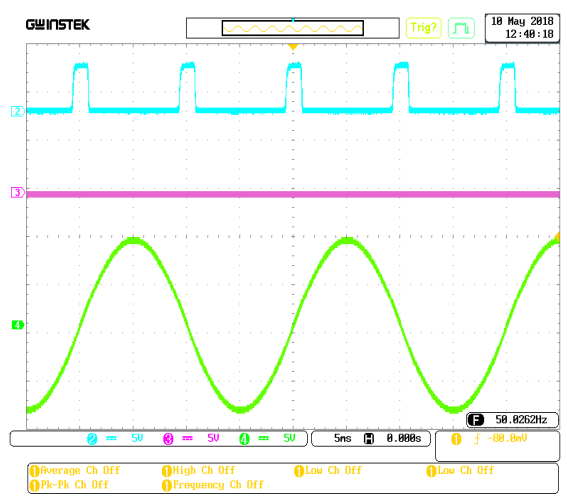

Figure 2.f Test with Firing Angle at 180 degrees

Figure 2. Motor control experiments

In Figure 2. c, Figure 2.d, Figure 2.e and Figure 2.f, the terminal voltage switched to a constant voltage at angle value close to $0^{\circ}, 45^{\circ}, 135^{\circ}$, and $180^{\circ}$ respectively. Finally, at $180^{\circ}$, the terminal voltage would be expected to not open at any angle which is obtained from Figure 2.f.

\subsection{Android Controller}

Testing of the Android controller is done in two parts: modular testing and full-system integration testing, which will be done in the next section.

For modular testing, the application was tested to interact with a single device at a time: either to the sensor or the motor. Figure 3.a contains the temperature reading from the sensor either from the sensor itself or from the manual polling via device list options in Figure 3.b. There is also a status report which is based on the last update timestamp from the sensor (Figure 3.a, second card). 


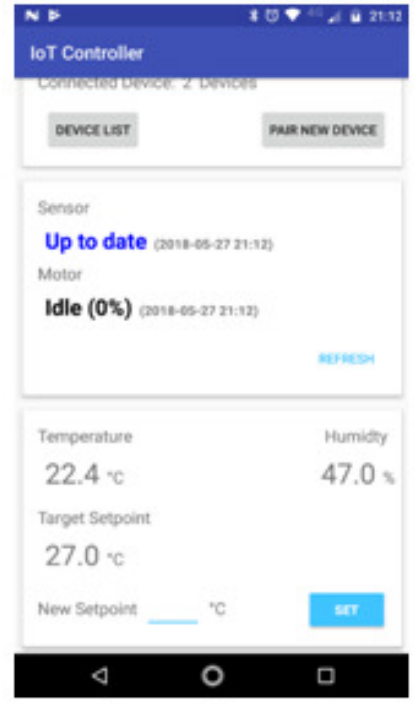

Figure 3.a Android Controller - Main View

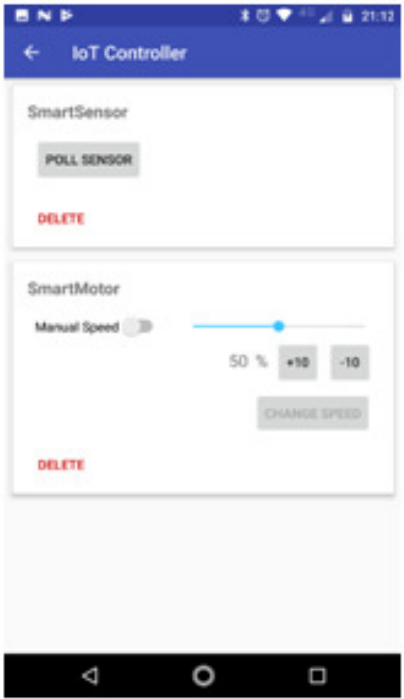

Figure 3.b Android Controller - Device List

Figure 3. App/Sensor experiments

\subsection{System integration}

This section explains the full-system integration test. The system is set up using an additional heater fan as the heating element to control the temperature reading of the sensor. The test begins with the heating fan heats up the temperature sensor to a temperature high enough so that the fan could cool down the temperature (i.e. much higher than the ambient temperature). Figure 4.a, shows the initial temperature reading after heating up the sensor. Then, the fan is turned on at full speed to cool down the sensor. After cooling down several degrees Celsius, the fan speed is slightly reduced as shown on Figure 4.b, because the difference in temperature and set point is now reduced

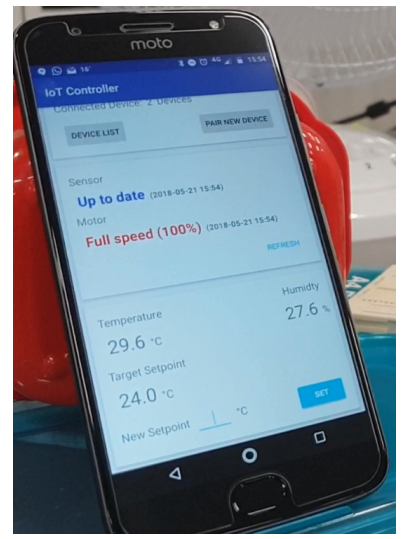

Figure 4.a Test - Initial State

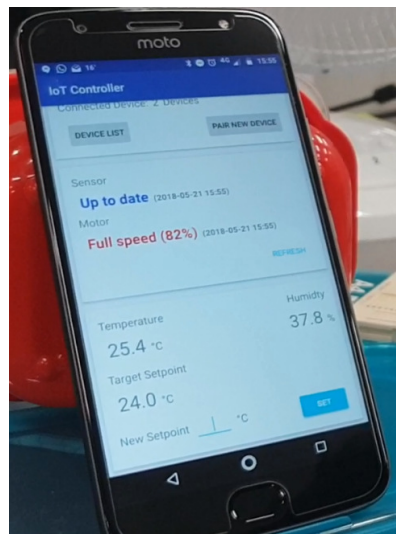

Figure 4.b Test - Fan Full Speed

Figure 4. System tests 


\section{MARKET STUDY}

Entrepreneurs and investors look for business opportunities with potential growing market [12]. Internet of Things (IoT) has a great potential to attract new and existing businesses. Where there is a potential market, analysing the profitability of a new product is a crucial steps in establishing and expanding a business. To achieve the expected rate of return an accurate product cost estimation is the key. It provides managers and investors with necessary information required for strategic decisions and achievement of business objectives. Mainly, in today's competitive environment, it is critical to have reliable product cost estimations for pricing decisions.

\subsection{Cost analysis}

To estimate our product cost, we use the total absorption costing method. Accordingly, the cost is divided to direct and indirect costs. Specifically, our product cost estimation consists of direct material, direct labour and overhead. The required direct materials and their costs are estimated as follows:

\begin{tabular}{|c|c|c|c|c|c|c|}
\hline Description & Qty & $\begin{array}{l}\text { Unit } \\
\text { (USD)* }\end{array}$ & Cost & $\begin{array}{l}\text { Unit } \\
\text { (AUD) }\end{array}$ & Cost & Total Cost (AUD) \\
\hline Conventional Fan & 1 & & & 14 & & 14 \\
\hline Arduino Uno - R3 SMD & 1 & 29.95 & & & & 38.935 \\
\hline Temp. Sensor DHT-22 & 1 & & & 9.95 & & 9.95 \\
\hline SparkFun Bluetooth Modem - BlueSMiRF Silver & 1 & 24.95 & & & & 32.435 \\
\hline Breadboard Jumper Wire Bundle & 1 & & & 4.95 & & 4.95 \\
\hline Female Headers & 2 & 1.5 & & & & 3.9 \\
\hline Break Away Headers - Straight & 2 & 1.5 & & & & 3.9 \\
\hline
\end{tabular}

*USD Rate 1 USD = 1.3 AUD

In our preliminary analysis, direct labour and overhead costs are estimated based on this assumption that the product will be produced in Australia (the product cost will vary if the location changes. The direct labour cost is estimated based on one hour assembly time at the rate of \$20. In addition, the estimated overhead costs are as follows for 1000 to 2000 units per year:

Table 3. breakdown of the manufacturing costs

\begin{tabular}{ll} 
Rent & 20,000 \\
Salaries & 50,000 \\
Equipment depreciation & 10,000 \\
Utilities & 10,000 \\
Other costs & 20,000 \\
\hline Total fixed overhead & $\$ 110,000$
\end{tabular}

In early stages of introducing a product, penetration pricing can be used as a strategy to attract customers through word of mouth [13]. Penetration pricing is setting a low price in the beginning of marketing campaign to gain a high market share. To attract more customers, for the first year we assume that we do not expect any profit and want to determine the selling price at a level that we can only cover all costs (both fixed and variable). To do so we use the break-even analysis technique. Break-even point is the number of products should be sold to cover all costs while making no profit. Break-even point analysis is a useful method to not only profit projection but also for pricing decision and expense control [14]. To calculate the break-even point the following items are required: fixed cost, selling price and variable cost. 
Accordingly, our suggested selling price is almost $\$ 185$ and break -even point is 1932 units.

Table 4. price calculations

\begin{tabular}{ll} 
Direct material (variable cost) & $\$ 108.07$ \\
Direct labour (variable cost) & $\$ 20$ \\
Overhead per unit & $\$ 57$ \\
\hline Unit cost & $\$ 185$
\end{tabular}

This cost estimation shows that if we produce and sell 1,932 units at the price of $\$ 185$, all costs will be covered.

As this pricing decision is made only for introducing the product to the market for the first year, different strategies are required to make profit in following years. To determine the alternatives we first discuss the value of our product from the customer point of view.

\subsection{Product values}

The Internet of Things can transform our various aspects of lives and enhance both efficiency of devices and comfort of individuals [15]. To analyse the impact of efficiency improvement of our product, the financial benefits that a customer will receive from using the product over a year are estimated. To do so, we first calculate the electricity cost of running a traditional $100 \mathrm{w}$ fan for the whole summer (90 days, 10 hours per day) for a household in Australia.

Table 5. Energy costs

\begin{tabular}{ll} 
Hours used & 900 \\
Energy consumption $(\mathrm{Kw})$ & $90 \mathrm{~kW}$ \\
Price $(\mathrm{kWh})$ & 0.35 \\
\hline Electricity cost & $\$ 31.5$
\end{tabular}

Our smart product might be able to reduce this electricity cost by $50 \%$. Comparing our estimated product price and the potential cost saving shows a significant gap. Specifically, more than 10 years electricity saving is required to justify the price. Thus, it can be argued that the electricity cost saving cannot attract customers and other values such as customers' comfort should be the focus which can affect our pricing model as well.

\section{Conclusions}

The summary of results and conclusion is basically divided into two sections that are as follows.

\subsection{Automation Section Conclusion}

A novel IoT based Fan speed control system has been designed and tested using IoT concepts. A computer program was developed to control the speed of the fan by using smart phone and is successfully implemented. The fan motor is operated and tested at different speed input value from the smart phone and the experimental results are noted. These results show that the user can switch on the fan, regulate its speed by using the smart phone. The user can operate this fan even he/she is in remote location. By using temperature and humidity sensors the speed control of fan becomes very easy so that it automatically changes its speed when the temperature is changed according to the user's comfort zone. All the values related to temperature, humidity and speed of the motor are also stored in the cloud storage, and the software can display these data for operators to check. The main advantage of this method of control is that the user can control the 
speed of the fan by giving the set point value via the smart phone. Therefore, the fan motor can be efficiently controlled by using the Wi-Fi directly from anywhere and anytime in this world with proper internet connection.

\subsection{Business Section Conclusion}

The preliminary cost analysis of our product shows that producing the product in Australia is not viable and further analysis is required to estimate the cost of production in Asian countries. Moreover, the monetary value of electricity cost saving of our product is not significant as the electricity consumption of a traditional fan is relatively low. Thus, the focus needs to be on the comfort aspects that our product can provide as well as adopting the technology to high-wattage devices. Specifically, the product can be used for patients, elderly or disabled people who cannot adjust the temperature manually. For example, it might not be possible for a person with disability to adjust the fan manually but using our product the adjustment will incur automatically and there is no need for human intervention. Finally, we suggest the use of our developed technology in this project for other electrical devices such as heaters and coolers with higher electricity consumption to provide both efficiency and comfort.

\section{ACKNOWLEDGEMENTS}

This research was supported by Swinburne University of Technology in collaboration with TJ Supply Limited Partnership under Seed Grant 35818.

\section{REFERENCES}

[1] S. Shimamura, K.Matsumoto, N.Maeda, T.Kodera, W. Nakagawa, Y. Shinozuka, M.Sugimoto and H.Saito, "Smart Fan: Self-contained Mobile Robot that performs Human detection and tracking using thermal Camera," International Conference on Artificial Reality and Telexistence Eurographics Symposium on Virtual Environments, 2014.

[2] Tajrin Ishrat, Mohammad Anisur Rahaman and Arif Ahammad, "Smart Fan for Human Tracking," the 9th International Forum on Strategic Technology (IFOST), October 21-23, 2014, Cox's Bazar, Bangladesh.

[3] Vaibhav Bhatia and Gavish Bhatia, "Room temperature based Fan Speed Control System using Pulse Width Modulation Technique," International Journal of Computer Applications (0975-8887) Volume 81-No5, November 2013.

[4] Md. Mozasser Rahman, Mohd Fahrul Radzi Bin Zakaria and Shahrul Na'im Sidek, "Sensory and Control System for Smart Fan," International Journal of Control, Automation and Systems, Vol.4 No.3, July2015, ISSN 2165-8277 (Print), ISSN 2165-8285 (Online).

[5] Pavithra. D and Ranjith Balakrishnan, "IoT based Monitoring and Control System for Hom Automation," Proceedings of 2015 Global conference on Communication Technologies (GCCT 2015).

[6] M.A.A. Mashud, Dilruba Yasmin, M.A. Razzaque and M.H. Uddin, "Automatic Room Temperature Controlled Fan Speed Controller using PT-100," International Journal of Scientific \& Engineering Research, Volume 6, Issue8, August-2015, ISSn 2229-5518.

[7] Zairi Ismael Rizman, Kim Ho Yeap, Nuraiza Ismail, Norizan Mohamad and Nur hafizah Rabi’ah Husin, "Design of Automatic Temperature Control System for Smart Fan using PIC," international Journal of Science and Research (IJSR), India Online ISSN:2319-7064. 
[8] Tarun Kumar Das and Yudhajit Das, "Design of a Room Temperature and Humidity Controller using Fuzzy Logic," American Journal of Engineering Research (AJER) e-ISSn:2320-0847 p-ISSN:23200936, Volume-02, Issue-11, pp-86-97.

[9] S. A. Gorji, M. Ektesabi and J. Zheng, "Isolated switched-boost push-pull DC-DC converter for stepup applications," in Electronics Letters, vol. 53, no. 3, pp. 177-179, 222017.

[10] S. Asghari and E. Fallah, "A new approach for efficiency optimizing of single-phase induction motors," 2012 3rd Power Electronics and Drive Systems Technology (PEDSTC), Tehran, 2012, pp. 500-505.

[11] Hamid M.B. Metwally, "New method for speed control of single phase induction motor with improved motor performance," Energy Conversion and Management 42 (2001) 941-950.

[12] Sahlman, W.A., 2008. How to write a great business plan (No. E70 90). Harvard Business School Press.

[13] Yenipazarli, A., 2015. A road map to new product success: Warranty, advertisement and price. Annals of Operations Research, 226(1), pp.669-694.

[14] Dean, J., 1948. Cost structures of enterprises and break-even charts. The American Economic Review, pp.153-164.

[15] Stojkoska, B.L.R. and Trivodaliev, K.V., 2017. A review of Internet of Things for smart home: Challenges and solutions. Journal of Cleaner Production, 140, pp.1454-1464. 